\title{
LETTERS
}

\section{Is it feasible to use indicators to collect data on asthma care performance in the primary care setting? A feasibility study}

\author{
*Teresa To ${ }^{a}$, Susan McLimont ${ }^{\mathrm{a}}$, Corinne Dalya ${ }^{a}$ Ginette Moores ${ }^{a}$, Andrea Gershon ${ }^{\mathrm{b}}$, Diane Lougheed \\ a Child Health Evaluative Sciences, The Hospital for Sick Children, Toronto, Ontario, Canada \\ b The Institute for Clinical Evaluative Sciences, Toronto, Ontario, Canada \\ c Department of Medicine, Queen's University, Kingston, Ontario, Canada
}

\footnotetext{
*Correspondence: Dr Teresa To, Senior Scientist, Child Health Evaluative Sciences, The Hospital for Sick Children, 555 University Avenue, Toronto, ON M5G 1X8 Canada. Tel: +1 (416) 813-8498 Fax: +1 (416) 813-5979 E-mail: teresa.to@sickkids.ca
}

Received 26th May 2011; revised 15th June 2011; accepted 19th June 2011; online 21st September 2011

(C) 2011 Primary Care Respiratory Society UK. All rights reserved

http://dx.doi.org/10.4104/pcrj.2011.00081

\section{Dear Sirs,}

Despite well-established management guidelines, variations in quality of asthma care exist and are common in primary care settings. ${ }^{1}$ Community-based quality of care (or performance) indicators can help identify barriers to, and enablers of, the development, dissemination and uptake of clinical guidelines for disease management. Despite the development and application of evidence-based performance indicators in diseases such as diabetes and stroke, ${ }^{2,3}$ the parallel in asthma is not well established. Klomp et al. ${ }^{4}$ developed indicators to measure asthma control, but fell short in providing a dynamic measure of asthma quality of care. There still remains a lack of standard asthma-specific quality of care indicators that measure process and health outcomes as part of a broader, comprehensive asthma surveillance system. Previously, using a modified Delphi approach, we developed a set of 15 evidence-based asthma performance indicators (APIs)..$^{5}$ The objective of this study was to test the feasibility of collecting patient data for these APIs as a means of measuring the quality of asthma care in primary care practice.

Five primary care sites across Ontario, Canada participated in the feasibility study. These sites were volunteers from an ongoing provincial Primary Care Asthma Program. To assess the utility of the APIs, we developed a data collection tool to aid primary health care (PHC) practitioners capture patient information. The tool, copyrighted as the Primary Care Asthma Performance Indicators Form "PC-API" (see see Appendix, available online at www.thepcrj.org) detailed the 15 APIs into nine categories: pulmonary function tests (PFTs) - including spirometry, peak flow or methacholine challenge; medication use; asthma control; exacerbations; health care use; action plan; asthma education; smoking cessation; and quality of life (QoL).

Participating sites were responsible for applying the PC-API Form to 10 randomly selected prospective patient visits and 10 randomly selected retrospective patients via chart abstraction. Patients with physician-diagnosed asthma were included. Those with co-morbidities (diabetes, cancer, COPD, arthritis, cardiovascular conditions) were excluded. Sites were provided with three options for submitting the PC-API Form: 1) hard copy paper; 2) electronically by email; or 3) web-based. The hard-copy paper form was completed manually by a PHC practitioner and submitted via postal service mail or fax. The electronic Adobe ${ }^{\circledR}$ PDF form was completed electronically and submitted as an encrypted attachment to an email or printed and then submitted via postal service mail or fax. The third option, used by most sites, was an electronic web-based form to be completed and submitted on-line to a secure web server housed at The Hospital for Sick Children in Toronto, Ontario, Canada. The pilot study spanned from June 1 until August 31, 2010 and collected API information for a total of 100 patients. Analyses were descriptive in nature, presented with overall means and proportions, and stratified by site, prospective and retrospective patient visits.

Overall, PHC practitioners reviewed the various versions of the PC-API Form as "feasible" and "practical to use". Our results (see Table) showed that the majority of patients' asthma diagnoses were confirmed by PFTs ( $76 \%$ and $74 \%$ in the prospective and retrospective study, respectively). However, use of PFTs for ongoing asthma monitoring in the previous 12 months was lower (66\% in the prospective and $61 \%$ in the retrospective study). While significant variations across the sites were observed, ranging from $10 \%$ to $100 \%$, the combined results can potentially be used as a "benchmark" for the respective indicator. Practices "performing" below the combined average may use it as a benchmark to improve delivery of care.

In general, patients in the prospective study showed a higher average number of inhaled corticosteroid prescriptions, lower average short-acting $\beta_{2}$-agonist (SABA) use, larger number of SABA-free days, and also a higher percentage of these patients had demonstrated their inhaler technique regularly compared to patients in the retrospective chart review. Forty-one percent of the prospective patients and $31 \%$ of the retrospective patients reported more than one asthma exacerbation in the previous 12 
Table 1. Means and variations of asthma performance indicators in prospective patients and retrospective chart abstraction patients

\begin{tabular}{|c|c|c|c|c|c|}
\hline API category & Definition of Asthma Performance Indicator & Patient visit $n=50$ * & Range & Chart Abstraction $\mathrm{n}=50$ * & Range \\
\hline \multirow{2}{*}{$\begin{array}{l}\text { Pulmonary } \\
\text { Function } \\
\text { Test (PFT) }\end{array}$} & $\begin{array}{l}\text { \% patient's asthma diagnosis confirmed by PFTs } \\
\text { (spirometry, peak flow or methacholine challenge) }\end{array}$ & $76 \%$ & $40-100 \%$ & $74 \%$ & $0-100 \%$ \\
\hline & $\%$ patients monitored with spirometry in last 12 months & $66 \%$ & $10-100 \%$ & $61 \%$ & $50-90 \%$ \\
\hline \multirow{5}{*}{$\begin{array}{l}\text { Medication } \\
\text { use }\end{array}$} & \% patients using inhaled corticosteroids (ICS) & $90 \%$ & $80-100 \%$ & $82 \%$ & $40-100 \%$ \\
\hline & $\begin{array}{l}\text { In last } 12 \text { months, average number of patient's self-reported } \\
\text { ICS prescription filled }\end{array}$ & 4.4 & $3.3-6.2$ & 3.8 & 1.3-5.1 \\
\hline & $\begin{array}{l}\text { In last } 4 \text { weeks, average number of patient's self-reported } \\
\text { short-acting } \beta_{2} \text {-agonist ( } 2 \text { puffs) per week }\end{array}$ & 3.6 & $1.7-5.6$ & 4.9 & $2.5-7.0$ \\
\hline & $\begin{array}{l}\text { In last } 4 \text { weeks, average number of patient's self-reported } \\
\beta_{2} \text {-agonist-free days }\end{array}$ & 21.9 & $19.1-25.6$ & 18.7 & $18.4-18.9$ \\
\hline & $\%$ patients have demonstrated their inhaler technique regularly & $84 \%$ & $60-100 \%$ & $68 \%$ & $10-100 \%$ \\
\hline \multirow{4}{*}{$\begin{array}{l}\text { Asthma } \\
\text { control }\end{array}$} & In last 6 months, \% patient's asthma symptoms control were assessed & $75 \%$ & $33-100 \%$ & $56 \%$ & $0-90 \%$ \\
\hline & In last 4 weeks, \% patient's asthma is well-controlled & $68 \%$ & $60-80 \%$ & $61 \%$ & $40-83 \%$ \\
\hline & $\begin{array}{l}\text { In last } 4 \text { weeks, average number of patient's self-reported days } \\
\text { symptom-free }\end{array}$ & 19.7 & $15.4-23.1$ & 18.5 & $18.3-18.6$ \\
\hline & $\begin{array}{l}\text { In last } 12 \text { months, average patient's self-reported days missed from } \\
\text { school or work due to asthma }\end{array}$ & 1.1 & $0-12$ & 0.8 & $0-10$ \\
\hline Exacerbations & In last 12 months, \% patients with more than 1 asthma exacerbation & $41 \%$ & $0-70 \%$ & $31 \%$ & $0-70 \%$ \\
\hline \multirow{4}{*}{$\begin{array}{l}\text { Health care } \\
\text { use }\end{array}$} & In last 12 months, average number of $E D$ visits for asthma & 0.4 & $0-12$ & 0.1 & 0.3 \\
\hline & In last 12 months, average number of urgent care visits for asthma & 0.1 & $0-2$ & 0.1 & $0-5$ \\
\hline & In last 12 months, average number of primary care visits for asthma & 2.5 & $0-12$ & 1.5 & $0-4$ \\
\hline & $\%$ patients with a routine healthcare provider & $100 \%$ & $100 \%$ & $100 \%$ & $100 \%$ \\
\hline Action plan & $\%$ patients received a written asthma action plan & $54 \%$ & $20-90 \%$ & $54 \%$ & $10-70 \%$ \\
\hline $\begin{array}{l}\text { Asthma } \\
\text { education }\end{array}$ & $\%$ patients referred to see a certified asthma educator & $98 \%$ & $90-100 \%$ & $94 \%$ & $70-100 \%$ \\
\hline \multirow{2}{*}{$\begin{array}{l}\text { Smoking } \\
\text { cessation }\end{array}$} & $\%$ patients who smoke & $12 \%$ & $0-20 \%$ & $17 \%$ & $0-30 \%$ \\
\hline & $\%$ smokers who have received advice to stop smoking & $50 \%$ & $0-100 \%$ & $100 \%$ & $100 \%$ \\
\hline $\begin{array}{l}\text { Quality } \\
\text { of life }\end{array}$ & $\begin{array}{l}\text { Average patient's assessment of quality of life } \\
1=\text { excellent, } 2=\text { very good, } 3=\text { good, } 4=\text { fair, } 5=\text { poor }\end{array}$ & 1.8 & 1.6-2.1 & 2.4 & 2.4 \\
\hline
\end{tabular}

months. A total of 19 emergency department, 3 urgent care and 124 primary care visits for asthma were reported among the prospective patients. Slightly higher numbers were reported from the retrospective review. About $12 \%$ of the prospective patients and $10 \%$ of the retrospective patients were smokers, and the majority $(75 \%)$ received advice to stop smoking. A 5-point scale was used to measure QoL in the prospective patients, indicating an average score of 1.8 across sites (suggesting very good to excellent QoL).

We have demonstrated that implementation of the 15 evidence-based APIs in community-based primary care practices is feasible. The collected data can help establish benchmarks for optimal health service delivery and identify areas for improvement in asthma care. Future direction includes the validation of the PCAPI Form across various populations, which will collect both provider- and population-level data to establish benchmarks for optimal asthma care in primary healthcare settings.

\section{Conflicts of interest}

The authors declare that they have no conflicts of interest in relation to this article.

\section{Contributorship}

Teresa To was responsible for the concept and design, interpretation of data, drafting and revising the manuscript. Teresa To and Corinne Daly participated in the interpretation of data, analysis and drafting the manuscript; Ginette Moores participated in the interpretation of data; and Susan McLimont, Andrea Gershon and Diane Lougheed assisted with revising the manuscript. All authors have approved the manuscript as submitted and take full responsibility for the manuscript.

\section{Funding}

This study was funded by the Canadian Institutes of Health Research [PHE - 85212]; the Government of Ontario; and the Public Health Agency of Canada. The opinions, results and conclusions reported in this paper are those of the authors and are independent from the funding sources. No endorsement by the Canadian Institutes of Health Research and Government of Ontario is intended or should be inferred. The views expressed herein do not necessarily represent the official policy of the Public Health Agency of Canada.

\section{References}

1. Katz A, Soodeen R, Bogdanovic B, De Coster C, Chateau D. Can the quality of care in family practice be measured using administrative data? Health Serv Res 2006;41(6):2238-54. http://dx.doi.org/10.1111/j.1475-6773.2006.00589.x

2. Ontario Health Quality Council. 2008 Report on Ontario's Health System. Toronto (ON); 2008 Contract No.: Document Number|.

3. Lewis M, Trypuc J, Lindsay P, O'Callaghan C, A. D. Has Ontario's Stroke System really made a difference? Healthc Q 2006;9(4):50-9.

4. Klomp H, Lawson JA, Cockcroft DW, et al. Examining asthma quality of care using a population-based approach. CMAJ 2008;178(8):1013-21. http://dx.doi.org/10.1503/cmaj.070426

5. To T, Guttmann A, Lougheed MD, et al. Evidence-based performance indicators of primary care for asthma: a modified RAND Appropriateness Method. Int J Qual Health Care 2010;22(6):476-85. http://dx.doi.org/10.1093/intqh/mzq061

See online Appendix 1 at www.thepcrj.org for online-only supplement 